\title{
Trans-national earthquake early warning (EEW) in north-eastern Italy, Slovenia and Austria: first experience with PRESTo at the $\mathrm{CE}^{3} \mathrm{RN}$ network
}

\author{
M. Picozzi ${ }^{1}$, L. Elia ${ }^{1}$, D. Pesaresi ${ }^{2}$, A. Zollo ${ }^{1}$, M. Mucciarelli ${ }^{2}$, A. Gosar ${ }^{3}$, W. Lenhardt ${ }^{4}$, and M. Živčić \\ ${ }^{1}$ RISSC, Università "Federico II" di Napoli - AMRA, Naples, Italy \\ ${ }^{2}$ CRS, OGS (Istituto Nazionale di Oceanografia e di Geofisica Sperimentale), Trieste, Italy \\ ${ }^{3}$ ARSO - Agencija Republike Slovenije za Okolje, Ljubljana, Slovenia \\ ${ }^{4}$ ZAMG - Zentralanstalt für Meteorologie und Geodynamik, Vienna, Austria
}

Correspondence to: M. Picozzi (matteo.picozzi@unina.it)

Received: 22 December 2014 - Revised: 23 March 2015 - Accepted: 2 April 2015 - Published: 12 May 2015

\begin{abstract}
The region of central and eastern Europe is an area characterised by a relatively high seismic risk. Since 2001, to monitor the seismicity of this area, the OGS (Istituto Nazionale di Oceanografia e di Geofisica Sperimentale) in Italy, the Agencija Republike Slovenije za Okolje (ARSO) in Slovenia, the Zentralanstalt für Meteorologie und Geodynamik (ZAMG) in Austria, and the Università di Trieste (UniTS) have cooperated in real-time seismological data exchange. In 2014 OGS, ARSO, ZAMG and UniTS created a cooperative network named the Central and Eastern European Earthquake Research Network $\left(\mathrm{CE}^{3} \mathrm{RN}\right)$, and teamed up with the University of Naples Federico II, Italy, to implement an earthquake early warning system based on the existing networks. Since May 2014, the earthquake early warning system (EEWS) given by the integration of the PRESTo (PRobability and Evolutionary early warning SysTem) alert management platform and the $\mathrm{CE}^{3} \mathrm{RN}$ accelerometric stations has been under real-time testing in order to assess the system's performance. This work presents a preliminary analysis of the EEWS performance carried out by playing back real strong motion recordings for the 1976 Friuli earthquake $\left(M_{\mathrm{W}}=6.5\right)$. Then, the results of the first 6 months of real-time testing of the EEWS are presented and discussed.
\end{abstract}

\section{Introduction}

With the aim of monitoring the seismic activity in the eastern sector of the Alps, since 2001 OGS (Istituto Nazionale di Oceanografia e di Geofisica Sperimentale) in Udine (Italy), the Agencija Republike Slovenije za Okolje (ARSO) in Ljubljana (Slovenia), the Zentralanstalt für Meteorologie und Geodynamik (ZAMG) in Vienna (Austria), and the University of Trieste (UniTS) have been collecting, analysing, archiving and exchanging seismic data in real time. The data exchange has proven to be effective and very useful in the case of seismic events at the borders between Italy, Austria and Slovenia, where the poor coverage of individual national seismic networks precluded a precise earthquake location. The usage of common data from the integrated networks improves significantly the overall capability of real-time event detection and rapid characterisation in this area. Furthermore, in 2014, OGS, ARSO, ZAMG and UniTS signed a memorandum of understanding naming the cooperative network as the Central and Eastern European Earthquake Research Network (CE ${ }^{3} \mathrm{RN}$ ) (Bragato et al., 2014).

Recently, in order to extend the seismic monitoring in north-eastern Italy, Slovenia and southern Austria towards earthquake early warning applications, OGS, ARSO and ZAMG teamed up with the RISSC-Lab group (http://www. rissclab.unina.it) of the Department of Physics at the University of Naples Federico II in Italy.

An earthquake early warning system (EEWS) is a realtime system integrating seismic networks and software capable of performing real-time data telemetry and analysis in 
order to issue alert messages within seconds from the origin of an earthquake and before the destructive S-waves generated by the event reach the users. When accompanied by appropriate training and preparedness of the population, an EEWS is an effective and viable tool for reducing the exposure of a population to seismic risk (e.g. Allen et al., 2009; Hoshiba, 2013; Picozzi et al., 2015a). The application of EEWS is nowadays increasing and several countries around the world have already developed EEWS, or are on the verge of doing so. Japan, Taiwan, Mexico, Romania and California, for example, already have operational EEWSs (e.g. Horiuchi et al., 2005; Wu and Zhao, 2006; Espinosa-Aranda et al., 2009; Böse et al., 2007, 2009). EEWSs are also under development and testing in other regions of the world, such as Italy, Turkey, Spain, and China (Satriano et al., 2010; Zollo et al., 2014; Alcik et al., 2009; Peng et al., 2011; Picozzi et al., 2014, 2015b).

The collaboration among OGS, ARSO, ZAMG and RISSC-LAB focuses on testing the EEW platform PRESTo (probabilistic and evolutionary early warning system: http://www.prestoews.org) in north-eastern Italy, Slovenia and Austria at the network $\mathrm{CE}^{3} \mathrm{RN}$, and represents, to our knowledge, the first worldwide attempt of implementing a trans-national EEWs. PRESTo is a stand-alone software system that processes live accelerometric streams from a seismic network to promptly provide probabilistic and evolutionary estimates of location and magnitude of detected earthquakes while they are occurring, as well as shaking prediction at the regional scale (Satriano et al., 2011).

Since 2014 PRESTo has run on OGS, ARSO and ZAMG data, by collecting and analysing in real time the data streams from 20 stations (Fig. 1).

In the following, first, we briefly present the $\mathrm{CE}^{3} \mathrm{RN}$ project, and we summarise the characteristics of EEWS and PRESTo. Then, we present the results of a test carried out by playing back the waveforms of the strong motion data of the $M_{\mathrm{W}}=6.5,1976$ Friuli earthquake, and, finally, we report on the performance of the EEW system during this preliminary testing phase.

\section{The $\mathrm{CE}^{3} \mathrm{RN}$ project}

The region of central and eastern Europe is an area characterised by a relatively high seismicity. The active seismogenic structures and the related potentially destructive events are located in the proximity of the political boundaries between several countries existing in the area. An example is the seismic region between north-eastern Italy (FriuliVenezia Giulia, Trentino-Alto Adige and Veneto), Austria (Tyrol, Carinthia) and Slovenia. So, when a destructive earthquake occurs in the area, all three countries are possibly af-

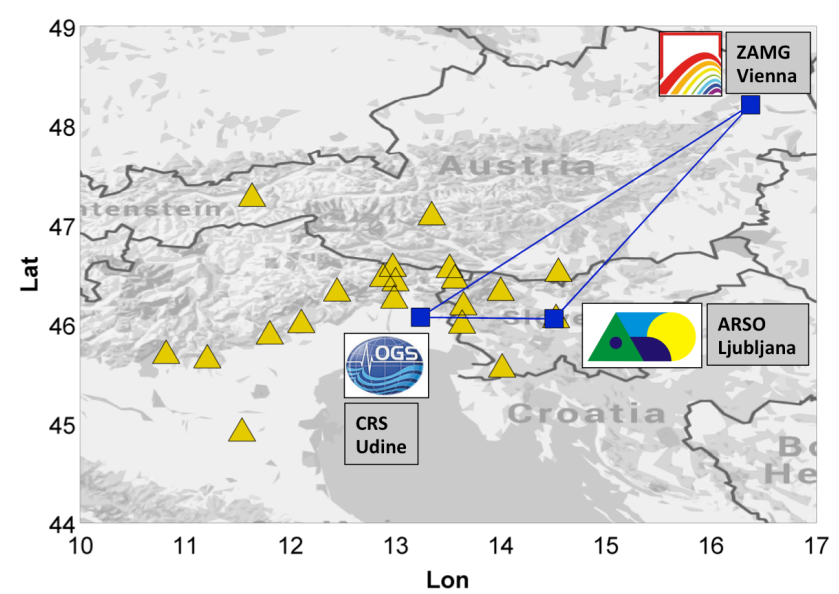

Figure 1. $\mathrm{CE}^{3} \mathrm{RN}$ institutions involved in the EEW experiment (blue squares), real-time accelerometric stations (yellow triangles).

fected. In the year 2001, the institutes OGS, ARSO, ZAMG, and UniTS signed an agreement for real-time seismological data exchange in the south-eastern Alps region. Soon after, the Interreg IIIa Italia-Austria Trans-National Seismological Networks in the South-Eastern Alps and FASTLINK projects started. The main goal of these projects was the creation of a transfrontier network for the common seismic monitoring of the region for scientific and civil defense purposes.

The OGS, ZAMG and ARSO seismic networks present many similarities. While there is a variety of sensor typologies in use (i.e. from strong motion to (very) broadband), all the stations are equipped with Quanterra data loggers $\left(Q_{6180}\right.$, $Q_{4120}, Q_{730}$ and $Q_{330}$ ), and similar strong motion sensors are used almost at each seismic station of the single networks. As shown by Stein and Reimiller (2014), the stations equipped with data logger Q330 are capable of delivering data with a latency of less than $1 \mathrm{~s}$, and therefore are suitable for early warning applications. The use of similar instrumentation facilitated a very important consequence of Interreg project Trans-National Seismological Networks in the SouthEastern Alps, and the adoption of common software suite Antelope from Boulder Real-Time Technologies (BRTT), for seismic data real-time acquisition, archiving, analysis and exchange. It is in fact straightforward, given that all the involved institutions use the same data acquisition software, to extend the single networks' seismic monitoring capabilities to the entire transfrontier network, thus acting like an extended virtual network. All the involved partners exchange waveforms and parametric data in real time through a network of bi-directional data links, mainly via the Internet, interconnecting all data centres.

During the recent past years, the high-quality data recorded by the trans-national network have been used by the involved institutions for their scientific research, for institutional activities and for civil defence services. Several common international projects have been realised with success. 


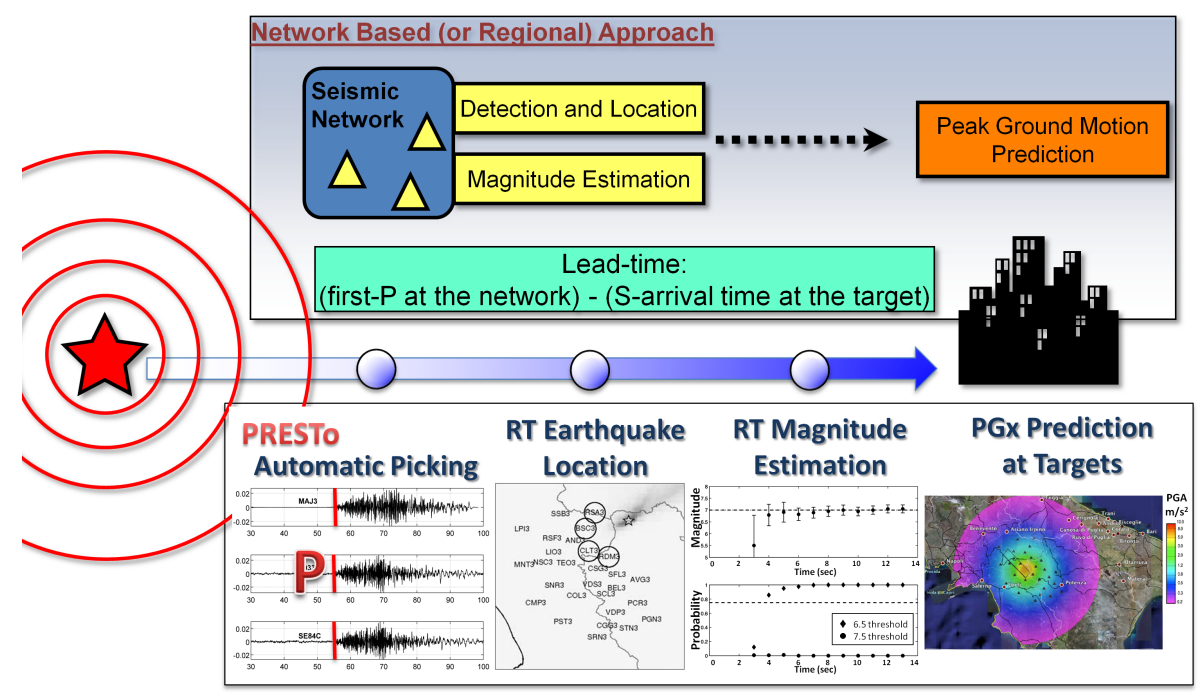

Figure 2. Schematic representation of the regional approach for EEW (modified from Satriano et al., 2011), and overview of the analyses carried out by the PRESTo software system for the real-time event characterisation and ground motion level at target site prediction.

The instrumentation has been continuously upgraded and the installations quality improved, as well as the data transmission efficiency.

In 2014, OGS, ARSO, ZAMG and UniTS signed a memorandum of understanding named the Central and Eastern European Earthquake Research Network $\left(\mathrm{CE}^{3} \mathrm{RN}\right)$ cooperative network (Bragato et al., 2014). $\mathrm{CE}^{3} \mathrm{RN}$ represents an excellent example of international high-quality research infrastructure and the starting point for the enlargement of the transfrontier network to all countries and their seismological institutions of the central and eastern Europe region. Furthermore, one of the main goals of the $\mathrm{CE}^{3} \mathrm{RN}$ is to intensify the cooperation between these institutions through common research activities and preparation of common international projects.

On 11 November 2014, the $\mathrm{CE}^{3} \mathrm{RN}$ partnership was enlarged to also include the Croatian Seismological Survey (CSS) of the University of Zagreb in Croatia.

\section{Earthquake early warning systems and PRESTo}

EEWS typically follows two basic approaches: "regional" (or network based), and "on-site" (or a single station). Regional EEWS are based on the use of a seismic network located near one or more expected epicentral areas, whose aim is to detect and locate an earthquake, and to determine its magnitude from the analysis of the first few seconds of the arriving $\mathrm{P}$-waves at multiple stations close to the epicentre (Satriano et al., 2011). On the other hand, on-site EEWS are based on seismic sensors deployed directly at the target site and exploit only the information carried by the faster early P-waves to infer the larger shaking related to the incoming $\mathrm{S}$ and surface waves.
One key parameter for an EEWS is the lead time, i.e. the time available to perform safety measures at distant targets once an earthquake has been promptly detected and characterised, and an alarm has been issued. The lead time for regional EEWS is defined as the travel-time difference between the arrival of the first $\mathrm{S}$-waves at the target site and the $\mathrm{P}$-waves recorded in the source area, after accounting for the necessary computation and data transmission times. In onsite EEWS, the lead time is equal to the difference in S- and $\mathrm{P}$-wave arrival times at the target itself.

Recently, Zollo et al. (2010) showed that the two approaches can be profitably integrated within a unique system that allows the early estimation of the potential damage zone (PDZ) associated with an event. Clearly, the integration of regional and on-site approaches is particularly useful whenever target sites are threatened by more than one seismic source area, and the latter are located at variable distances from the target sites. An exhaustive review of the concepts, methods, and physical basis of EEWS has been presented by Satriano et al. (2010).

PRESTo is a free and open source, highly configurable and easily portable platform for earthquake early warning (Iannaccone et al., 2010). PRESTo processes the real-time accelerometric data streams from the stations of a seismic network to promptly detect the P-wave arrival, provide the probabilistic and evolutionary estimates of location and magnitude of earthquakes while they are occurring, as well as the shaking prediction on a regional scale (Fig. 2). Alarm messages containing the continuously updated estimates of source and ground motion at target parameters, and their associated uncertainties, are sent over the Internet, and can thus also reach distant vulnerable infrastructures before the arrival of destructive waves, enabling the activation of automatic 
safety procedures. Following the idea proposed by Zollo et al. (2010), PRESTo implements both a regional and an onsite approach.

In its regional configuration (Fig. 2), PRESTo uses (a) a phase detector and picker algorithm, which is optimised for real-time seismic monitoring and EEW (Lomax et al., 2012); (b) a location algorithm, RTLoc (Satriano et al., 2008), which locates earthquakes using information from both triggered and not-yet-triggered stations, and which provides a fully probabilistic description of the hypocentre coordinates and origin time; (c) the RTMag algorithm (Lancieri and Zollo, 2008), a Bayesian approach that uses the peak displacement (Pd) measured on the first seconds of the high-passfiltered signal on short time windows of P-waves (i.e. 2 and $4 \mathrm{~s}$ ) and S-waves (i.e. 1 or $2 \mathrm{~s}$ ), and empirical correlation laws between this latter parameter and the final earthquake magnitude $(M)$; and (d) finally, ground motion prediction equations (GMPE) that allow one to predict the peak ground motion at target sites and at seismic stations using EEW location and magnitude estimates.

The regional approach to early warning is integrated with an on-site, threshold-based method for the definition of independent local alert levels at each station. To this aim, the dominant period, $\tau_{c}$, and the peak displacement in a short time window after the first P-arrival time, Pd, are simultaneously measured at each station, independently of the rest of the seismic network. As shown by Zollo et al. (2010), Pd can be correlated with the final PGV and consequently with the modified Mercalli intensity $\left(I_{\mathrm{MM}}\right)$, which is a measure of the expected damage, while $\tau_{c}$ can be correlated with the earthquake magnitude. These two parameters are compared with threshold values that define a decisional table with four alert levels, declaring the expected earthquake effects nearby the station or at distant sites. The alert level can be used to initiate safety measures at each site independently of the regional processing. At the same time, on the regional scale, the local alert levels, as they become available, can be combined with the estimated source parameters to define the extent of the potential damage zone (PDZ), i.e. the area in which the highest intensity levels are expected (Zollo et al., 2010).

Since 2009, PRESTo has been under real-time experimentation in southern Italy on the data streams of the Irpinia Seismic Network (ISNet). Moreover, in order to analyse its performance in different seismic hazard contexts and seismic networks of varying extensions, PRESTo is also currently operating in other seismological centres (e.g. at the Korean Institute of Geoscience and Mineral Resources, KIGAM, in South Korea, at the Kandilli Observatory and Earthquake Research Institute, KOERI, in Turkey, and at the National Institute of Research and Development for Earth Physics, NIEP, in Romania). In addition, the feasibility study of a nationwide early warning system in Italy using the National Accelerometric Network (RAN) and PRESTo is in progress.

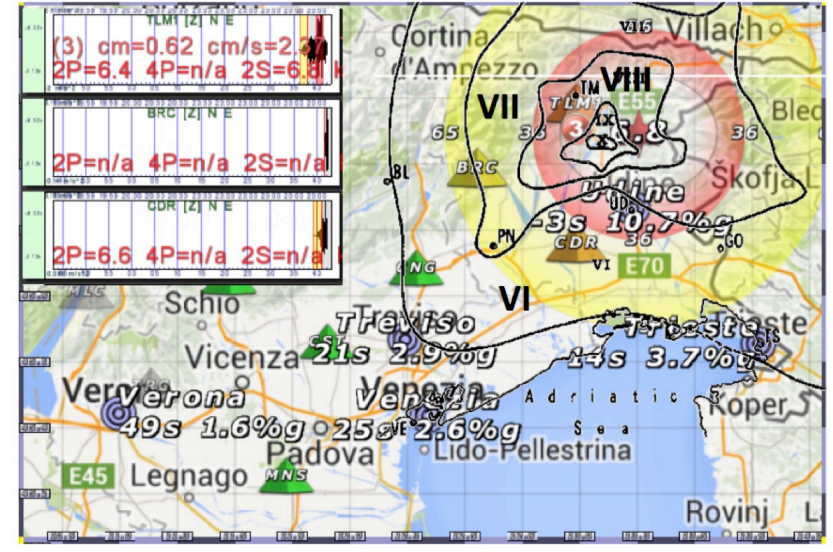

Figure 3. Snapshot of the PRESTo system during the playback of the $M_{\mathrm{W}}=6.5,1976$ Friuli earthquake, at the instant when three stations have triggered and the first alert is issued.

\section{EEW analysis of the 1976 Friuli earthquake data}

One of the first tests that we carried out was devoted to verifying what could have been the performance of PRESTo in the case of the $1976, M_{\mathrm{W}}=6.5$ Friuli earthquake in northern Italy (Carulli and Sleiko, 2005). To this aim, we realised an off-line run of the algorithm (i.e. a playback) of this earthquake using the historical recordings downloaded by ITACA 2.0 (Luzi et al., 2008; Pacor et al., 2011). The playback was run considering the network geometry of 1976, but assuming the existence at the time of the hardware and the management software necessary for the real-time data streaming to the OGS's seismological centre of Udine.

Figure 3 shows a snapshot of the first event detection and characterisation provided by PRESTo at the instant when only three stations have triggered and the first alert is issued. Although based on few initial P-measurements, the early magnitude estimation with only two stations $\left(M_{L}=6.8\right)$ is close to the final value (i.e. 6.5) as inferred from authoritative catalogues.

The blind zone is the region where $\mathrm{S}$-waves arrive before the first alert is issued, and it corresponds to the circular area where no lead time is available and no safety actions can be undertaken. Given the station's available density at that time, we observe that the blind zone has a radius of $36 \mathrm{~km}$. Despite the fact that, under such conditions, the municipalities affected by the most severe damage level could not have been alerted, the comparison with the macroseismic field estimated by Giorgetti (1976) shows that some of the municipalities in the area of intensity VII and most of those in the area of intensity VI could have potentially received an alert (Fig. 3). For instance, at the city of Pordenone (falling within the area of intensity VII and located about $65 \mathrm{~km}$ from the epicentre), we measure a lead time of about $9 \mathrm{~s}$. Furthermore, for the area included within isoseismal level VI (i.e. where the perceived ground shaking level is strong), the lead time 
could have been between about 15 and 20 s (e.g. $14 \mathrm{~s}$ for Trieste, and $21 \mathrm{~s}$ for Treviso, Fig. 3). Considering the network geometry that exists nowadays, we estimated that, for an event with the same epicentre of the 1976 one, the blind zone radius may shrink to about $22 \mathrm{~km}$. For instance, in the case of Pordenone, the lead time might increase to about $13 \mathrm{~s}$.

Figure 4 shows, still for the playback of the Friuli 1976 earthquake, the PDZ obtained estimated from the Pd measurements at the instant when the first four stations have triggered. Interestingly, despite the PDZ not showing the complex shape of isoseismal level VII, this was somehow expected given the few stations available for the analysis; in first approximation this early estimation of the damage extension matches reasonably well with the size of the observed damage zone by Giorgetti (1976). As shown by Colombelli et al. (2012) on Japanese data examples, whenever a dense network of stations is available, the PDZ maps can reproduce the extension of the damage area well (i.e. the area for which the observed macroseismic intensity is larger than VII).

\section{PRESTo performance on $\mathrm{CE}^{3} \mathrm{RN}$}

Since the beginning of 2014, PRESTo (version 0.2.7) has been under experimentation in the transnational area including north-eastern Italy, Slovenia and Austria. During this preliminary test phase, in order to avoid overloading the Antelope system managing the $\mathrm{CE}^{3} \mathrm{RN}$, a dedicated SeisComP server (SeisComP, 2009) has been set up at the OGS CRS data centre in Udine with the aim of collecting and converting in SeedLink (Heinloo, 2000) the data of 20 accelerometric stations from the Antelope system (Fig. 1), and pushing them towards a dedicated PRESTo system at RISSC-Lab in Naples.

After an initial period during which we tested different setups of the system parameters, since the end of March 2014 we have been experimenting with the velocity model used for routine earthquake analysis and bulletin production at OGS (OGS, 1995-2013); a minimum number of five stations required to trigger within $12 \mathrm{~s}$ for event declaration; the coefficients of the empirical correlation laws between the peak displacement (Pd) measured on short time windows of P-waves and the earthquake magnitude (M) estimated by Lancieri and Zollo (2008); and the Akkar and Bommer (2007) ground motion prediction equation.

Since the station distribution has a key role in determining the resilience of a system, that is to say the network rapidity in issuing EEW alerts, we estimated for the $\mathrm{CE}^{3} \mathrm{RN}$ network the time of the first alert and the blind-zone extent when three stations have triggered (Fig. 5). The analysis was carried out considering a grid of virtual seismic sources (i.e. a node each of $0.05^{\circ} \times 0.05^{\circ}$ for a total of 9801 nodes) with a fixed depth at $6.4 \mathrm{~km}$.

Following Picozzi et al. (2015b), the time of the first alert is defined as the time when P-waves reached the third station

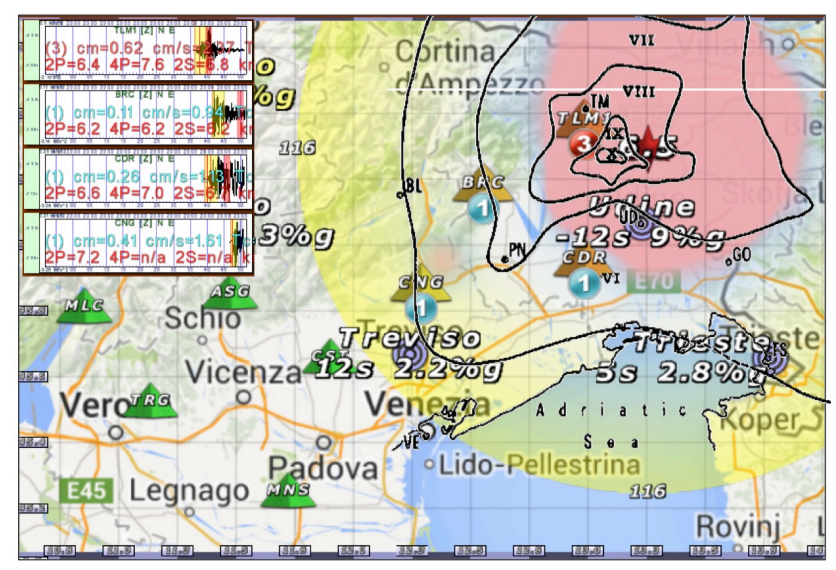

Figure 4. Same as Fig. 3 but showing the PDZ (pink area) corresponding to real-time estimation of the area with macroseismic intensity equal to or higher than VII.

of the network. Furthermore, the BZ is defined as the sum of three delays: (1) the time of the first alert, (2) a fixed delay for the telemetry and computation equal to $2 \mathrm{~s}$, selected according to the value recorded with PRESTo at the ISNet accelerometric network in southern Italy over a long period of testing (Satriano et al., 2011), and (3) the constraint of having $2 \mathrm{~s}$ long $\mathrm{P}$-wave time windows at an $\mathrm{N}-1$ station used by RTLoc, which is the needed information for RTMag to estimate the magnitude. This latter constraint is due to the fact that at the instant when RTLoc locates an event with $\mathrm{N}$ stations, RTMag provides the first magnitude estimation using $\mathrm{N}-1$ stations, under the condition that they recorded at least $2 \mathrm{~s}$ of P-waves. Finally, the sum of these three times is converted in the radius of BZ by multiplying it by the $\mathrm{S}$-wave velocity, assuming that this latter value is equal to $3 \mathrm{~km} \mathrm{~s}^{-1}$.

Figure 5a shows that the time of the first alert is less than or equal to $10 \mathrm{~s}$ for the central area of the network, which includes the Friuli 1976 earthquake's epicentre and the ItalianSlovenian boundary, where the station's density is high. The first alert time, and the smallest as well as the larger values, are in general elongated approximately in the east-west direction, according to the network geometry. Also, the blindzone map shows a similar trend, having the smallest values (i.e. below $25 \mathrm{~km}$ ) in the Friuli 1976 earthquake's epicentre area, with larger values towards the network boundaries (Fig. 5b).

Concerning the real-time testing of the EEWS, since the end of May 2014, that is to say when a stable configuration of the EEWS was found, PRESTo (version 0.2.7) detected in real time 23 earthquakes, while one event was missed (i.e. event no. 21, Table 1).

Figure 6 shows that the performance of the system in locating the earthquakes has in general been very good, with 18 events out of 23 located within $10 \mathrm{~km}$ of the authoritative value. Only in one case is the discrepancy between 10 and $50 \mathrm{~km}$, and in four cases it is larger than $50 \mathrm{~km}$. Concerning 
a)

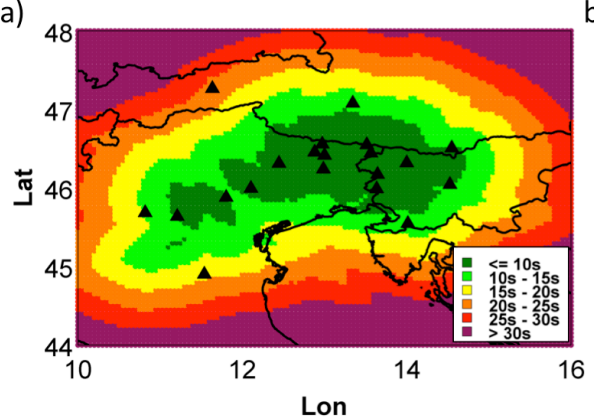

b)

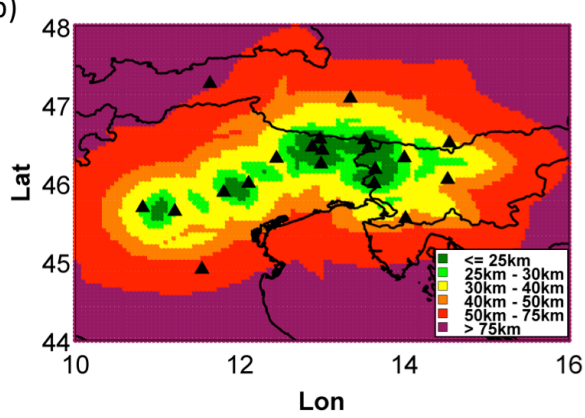

Figure 5. Distribution of time of the first alert (a) and dimension of the blind zone (b) for the grid of synthetic sources.

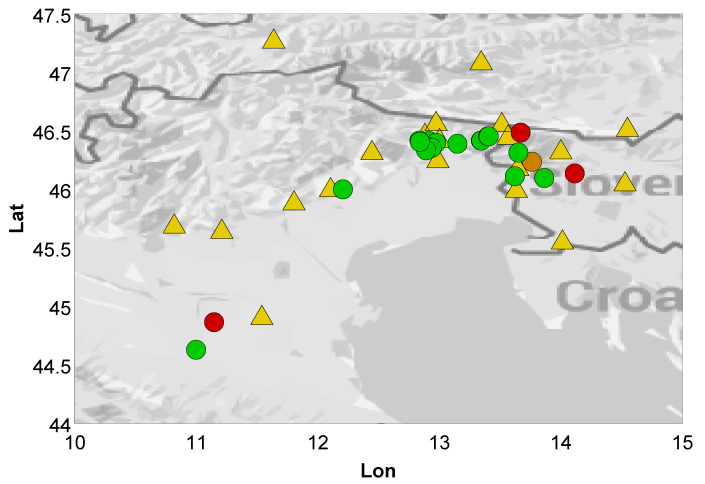

Figure 6. $\mathrm{CE}^{3} \mathrm{RN}$ stations (yellow). Location error within $10 \mathrm{~km}$ (green), between 10 and $50 \mathrm{~km}$ (orange), and larger than $50 \mathrm{~km}$ (red).

the depth estimation, it must be kept in mind that $90 \%$ of the events in this region are related to a seismogenic layer placed at a depth of about $8 \mathrm{~km}$ (Gruppo di lavoro MPS, 2004). The peculiar distribution of events in depth, together with the observation that, given the Pd vs. $M$ relationship adopted, location discrepancies of the order of $15 \mathrm{~km}$ determine a magnitude error within 0.5 magnitude units, led the depth estimation to be, for the moment, a parameter of minor importance in our experiment. Similarly to what was already observed in the Irpinia region (Satriano et al., 2011), the hypocentral locations for the events inside the network are generally well constrained starting from the very first estimates. For the events outside the network, the azimuth is well determined, but there is typically a larger uncertainty in the distance.

In order to quantitatively assess the EEWS performance, we compared the EW magnitude $\left(M_{\mathrm{EW}}\right)$ with the authoritative one $\left(M_{\mathrm{BULL}}\right)$, and we declared success (S) when $M_{\mathrm{EW}}$ falls within a \pm 0.5 interval around $M_{\mathrm{BULL}}$, missed (M) when $M_{\mathrm{EW}}$ is lower than $M_{\mathrm{BULL}}-0.5$ units, and false (F) when $M_{\mathrm{EW}}$ is higher than $M_{\mathrm{BULL}}+0.5$ units. Table 1 shows that the system had 17 successful detections $(70.8 \%), 3$ false detections $(12.5 \%)$, and 4 missed events $(16.7 \%)$, of which

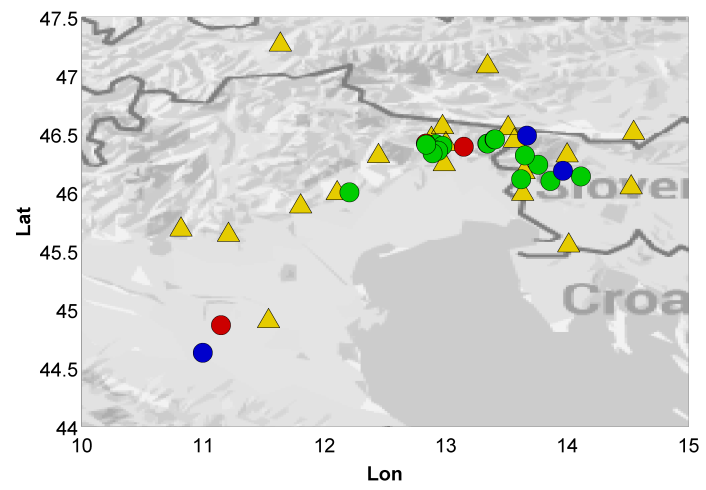

Figure 7. Same as Fig. 1 but showing the correctly detected (green), missed (red), and false (blue) events.

2 were detected but with underestimated magnitude, 1 was a $M_{\mathrm{B}}, 5$ occurred in Greece (event no. 20, http://cnt.rm.ingv.it), and 1 was not detected (event no. 2). In general, we observed that both the mis-detection and the wrong location and magnitude estimation occurred when the events were located out of the network, or where the latter has a lower station density (i.e. no. 16 , no. 20 , and no. 21 , Table 1 ). On the contrary, Fig. 7 shows that when the events occur in the area of higher station density, which also corresponds to higher seismic risk areas, the estimation of EEW magnitude is generally correct. Figure 8 shows, as an example, the good detection of event no. 1 (Table 1) that occurred in Slovenia.

Recently, on the occasion of the $M=4.1$ event that occurred nearby the town of Udine, Italy (i.e. event no. 24 of 30 January 2015; Table 1), we observed that PRESTo provided a correct location, but estimated an EW magnitude 0.6 units less than the authoritative one $\left(3.5 M_{\mathrm{EW}}\right.$, 4.1 $\left.M_{\mathrm{BULL}}\right)$. The location being accurate, we guessed that the discrepancy between the early warning and the bulletin magnitude estimates might be related to the parameters of the peak displacement $(\mathrm{Pd})$ vs. $M$ relationships. We decided to investigate this case in more detail by using the recordings of this event to run an off-line PRESTo playback. In particular, the playback was run using new parameters of the 
Table 1. Earthquake detected by PRESTo at $\mathrm{CE}^{3} \mathrm{RN}$ during the period from May to December 2014. The early warning (EW) estimates are compared with those of the OGS-CRS bulletin (BULL; from OGS, 1995-2013). EEW performance: success (S), missed (M), false (F).

\begin{tabular}{|c|c|c|c|c|c|c|c|c|c|c|}
\hline ID & $\begin{array}{l}\text { Date (yyyy- } \\
\text { mm-dd) and } \\
\text { time (UTC) }\end{array}$ & $\begin{array}{c}M_{\text {BULL }} \\
( \pm 0.3)\end{array}$ & $\begin{array}{c}\text { LonBULL } \\
\left({ }^{\circ}\right)\end{array}$ & $\begin{array}{c}\text { LatBULL } \\
\left(^{\circ}\right)\end{array}$ & $M_{\mathrm{EW}}$ & $\begin{array}{c}\text { Lon }_{\text {EW }} \\
\left(^{\circ}\right)\end{array}$ & $\begin{array}{c}\text { Latew } \\
\left({ }^{\circ}\right)\end{array}$ & $\begin{array}{l}M_{\mathrm{EW}-} \\
M_{\mathrm{BULL}}\end{array}$ & $\begin{array}{r}\text { Time first } \\
\text { info loc. } \\
\& M(\mathrm{~s})\end{array}$ & $\begin{array}{l}\text { EEW } \\
\text { perf. }\end{array}$ \\
\hline 1 & $\begin{array}{c}29 \text { May } 2014 \\
07: 24: 18.63\end{array}$ & 3.8 & 13.862 & 46.098 & 3.5 & 13.8511 & 46.0967 & -0.3 & 10.0 & S \\
\hline 2 & $\begin{array}{c}2 \text { Jun } 2014 \\
02: 15: 03.02\end{array}$ & 2.0 & 12.915 & 46.414 & 2.0 & 12.9662 & 46.4153 & 0 & 13.8 & S \\
\hline 3 & $\begin{array}{l}19 \text { Jun } 2014 \\
11: 26: 21.40\end{array}$ & 2.6 & 14.114 & 46.137 & 2.8 & 14.1955 & 45.4527 & 0.2 & 15.5 & S \\
\hline 4 & $\begin{array}{l}24 \text { Jun } 2014 \\
22: 43: 25.39\end{array}$ & 2.7 & 13.762 & 46.237 & 2.8 & 13.9952 & 46.6362 & 0.1 & 40.2 & $S$ \\
\hline 5 & $\begin{array}{l}29 \text { Jun } 2014 \\
18: 39: 32.15\end{array}$ & 2.1 & 12.916 & 46.414 & 1.9 & 12.8762 & 46.3952 & -0.2 & 50.2 & $S$ \\
\hline 6 & $\begin{array}{c}5 \mathrm{Jul} 2014 \\
15: 01: 14.57\end{array}$ & 1.7 & 13.342 & 46.418 & 1.8 & 13.3719 & 46.4447 & 0.1 & 32.8 & $S$ \\
\hline 7 & $\begin{array}{c}5 \mathrm{Jul} 2014 \\
15: 47: 05.50\end{array}$ & 1.6 & 13.344 & 46.418 & 1.7 & 13.3719 & 46.4547 & 0.1 & 51.6 & S \\
\hline 8 & $\begin{array}{c}7 \mathrm{Jul} 2014 \\
10: 50: 38.87\end{array}$ & 2.8 & 12.206 & 46.001 & 3.1 & 12.3071 & 45.9876 & 0.3 & 14.1 & S \\
\hline 9 & $\begin{array}{l}20 \mathrm{Jul} 2014 \\
14: 44: 13.58\end{array}$ & 2.4 & 13.668 & 46.486 & 3.7 & 10.2293 & 45.0643 & 1.3 & 71.5 & $\mathrm{~F}$ \\
\hline 10 & $\begin{array}{l}25 \mathrm{Jul} 2014 \\
06: 32: 00.58\end{array}$ & 1.9 & 12.972 & 46.398 & 1.6 & 12.9662 & 46.3952 & -0.3 & 68.1 & $S$ \\
\hline 11 & $\begin{array}{l}8 \text { Aug } 2014 \\
12: 14: 16.38\end{array}$ & 2.6 & 12.917 & 46.361 & 3.1 & 12.9325 & 46.3502 & 0.5 & 13.2 & S \\
\hline 12 & $\begin{array}{c}\text { 1 Sep } 2014 \\
00: 50: 52.70\end{array}$ & - & - & - & 2.3 & 13.9646 & 46.1859 & - & 23.9 & $\mathrm{~F}$ \\
\hline 13 & $\begin{array}{l}\text { 12 Sep } 2014 \\
15: 50: 52.85\end{array}$ & 2.2 & 13.401 & 46.455 & 2.0 & 13.4283 & 46.4495 & -0.2 & 21.2 & $S$ \\
\hline 14 & $\begin{array}{l}12 \text { Sep } 2014 \\
15: 53: 45.06\end{array}$ & 2.0 & 13.405 & 46.455 & 2.0 & 13.4735 & 46.4694 & 0 & 57.0 & $S$ \\
\hline 15 & $\begin{array}{l}18 \text { Sep } 2014 \\
14: 24: 41.45\end{array}$ & 2.2 & 12.937 & 46.356 & 1.8 & 12.9325 & 46.3502 & -0.4 & 11.5 & $\mathrm{~S}$ \\
\hline 16 & $\begin{array}{c}5 \text { Oct } 2014 \\
07: 09: 23.00\end{array}$ & 2.5 & 10.997 & 44.631 & 3.9 & 11.0858 & 44.6298 & 1.4 & 180.5 & $\mathrm{~F}$ \\
\hline 17 & $\begin{array}{l}22 \text { Nov } 2014 \\
03: 22: 35.41\end{array}$ & 1.9 & 13.650 & 46.316 & 2.0 & 13.6748 & 46.3382 & 0.1 & 103.9 & $S$ \\
\hline 18 & $\begin{array}{l}\text { 5 Dec } 2014 \\
09: 11: 36.31\end{array}$ & 2.8 & 12.835 & 46.418 & 2.2 & 12.8357 & 46.4183 & -0.6 & 11.5 & M \\
\hline 19 & $\begin{array}{c}7 \text { Dec } 2014 \\
08: 00: 32.35\end{array}$ & 1.8 & 13.620 & 46.113 & 2.1 & 13.6208 & 46.1138 & 0.3 & 92.1 & $S$ \\
\hline 20 & $\begin{array}{l}11 \text { Dec } 2014 \\
22: 26: 02.39\end{array}$ & 4.9 & 20.444 & 38.478 & 3.7 & 14.5266 & 44.6075 & -1.2 & 44.6 & M \\
\hline 21 & $\begin{array}{l}12 \text { Dec } 2014 \\
07: 01: 25.00\end{array}$ & 3.5 & 11.146 & 44.866 & & - & - & - & & $\mathrm{M}$ \\
\hline 22 & $\begin{array}{l}18 \text { Jan } 2015 \\
14: 42: 23.98\end{array}$ & 2.9 & 12.890 & 46.335 & 2.7 & 12.8538 & 46.3351 & -0.2 & 12.0 & $S$ \\
\hline 23 & $\begin{array}{l}22 \text { Jan } 2015 \\
15: 34: 35.27\end{array}$ & 1.7 & 12.838 & 46.408 & 1.3 & 12.8311 & 46.4151 & -0.4 & 10.2 & $\mathrm{~S}$ \\
\hline 24 & $\begin{array}{l}\text { 30 Jan } 2015 \\
00: 45: 48.51\end{array}$ & 4.1 & 13.148 & 46.391 & 3.5 & 13.1463 & 46.3751 & -0.6 & 8.4 & M \\
\hline
\end{tabular}




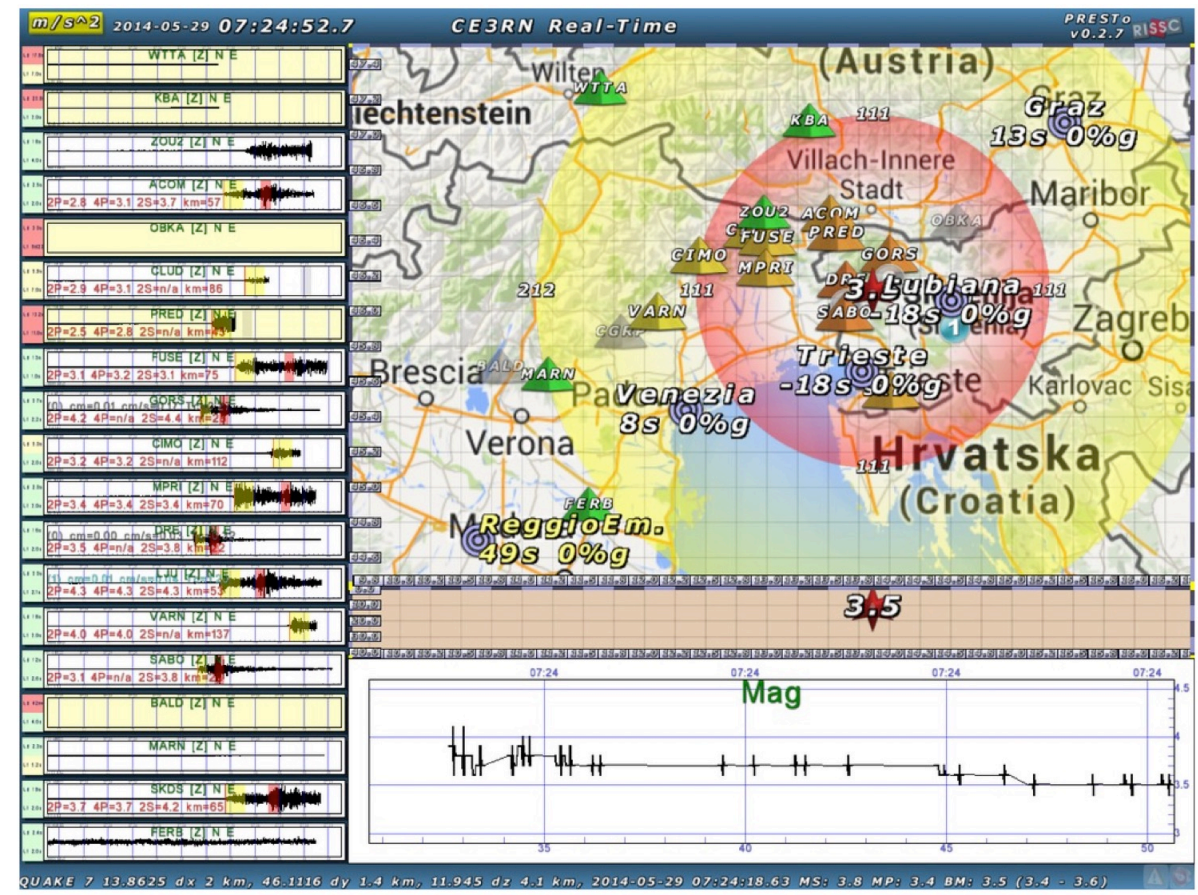

Figure 8. Snapshot of the PRESTo system during the 29 May $2014 M_{\mathrm{L}}=3.8$ Slovenian earthquake (event no. 1, Table 1).

Pd vs. $M$ relationship derived from the local magnitude law used by the INGV. Figure 9 shows that the new law provides potential $M_{\mathrm{EW}}$ estimates in better agreement with the $M_{\mathrm{BULL}}$ (4.2 $\left.M_{\mathrm{EW}}, 4.1 M_{\mathrm{BULL}}\right)$. However, it is worth mentioning that the magnitude law used by the INGV is the one computed for the southern California region, which mostly adheres to actual Italian data for station-hypocentre distances greater than $100 \mathrm{~km}$, whereas it overestimates the local magnitude at closer stations (M. Di Bona, personal communication, 2015; http://iside.rm.ingv.it). More tests on this point are needed before drawing a conclusion.

Concerning the few wrong event characterisations, we guess that the low magnitude of the events might have played a major role. Indeed, small magnitudes lead to a low signalto-noise ratio of the recordings, which in turn makes the realtime analysis more difficult than in the case of moderate size events. This issue can be overcome by considering velocity streams, a feature that we included in the newest version of PRESTo (PRESTo 0.2.8; http://www.prestoews.org) and that in the near future will also be adopted at $\mathrm{CE}^{3} \mathrm{RN}$.

The time when the first EEW information on the location and magnitude of the earthquake was available is also reported in Table 1 , as the time after the first $\mathrm{P}$ arrival detected at a $\mathrm{CE}^{3} \mathrm{RN}$ station (Fig. 10). We observe that, in 10 cases, the EEW information is available within $15 \mathrm{~s}$ (the minimum value of $8.4 \mathrm{~s}$ has been observed for event no. 24 of 30 January 2015), while in 13 cases the delay was larger than $15 \mathrm{~s}$ (the maximum vale was $180.5 \mathrm{~s}$ for event no. 16 of 22 November 2014). The spatial distribution of the delays
(Fig. 10) highlights that, for EEW purposes, the reasons for the larger telemetry delays of stations in the Slovenian sector should be better investigated.

\section{Conclusions}

This work presents the preliminary results of a feasibility study carried out with EEW platform PRESTo in the high seismic hazard region including north-eastern Italy, Slovenia and Austria, where the 1976 Friuli earthquake occurred.

Results from the offline analysis using the software platform for EW, PRESTo, indicate that, despite the network geometry at that time being rather poor, the EEWS could have been potentially very useful. Indeed, we estimated that the blind-zone radius could have been of the order of $36 \mathrm{~km}$, and that municipalities located within the intensity VI and VII areas could have potentially benefited from an alert. Of course, implementing an EEWS requires, besides these scientific aspects, many further issues to be taken into consideration. For instance: the definition of actions that end users could effectively put into operation within the available lead time for the reduction of their exposure to the seismic risk; cost-benefit analysis of the aforementioned actions; the definition, test, and validation of the procedures which allow the implementation of these mitigation actions; a comprehensive campaign of information on what has to be done; and, finally, a clear attribution of the responsibilities.

Interestingly, we also found that, in the case of a large event with a similar epicentre to the 1976 Friuli earthquake, 


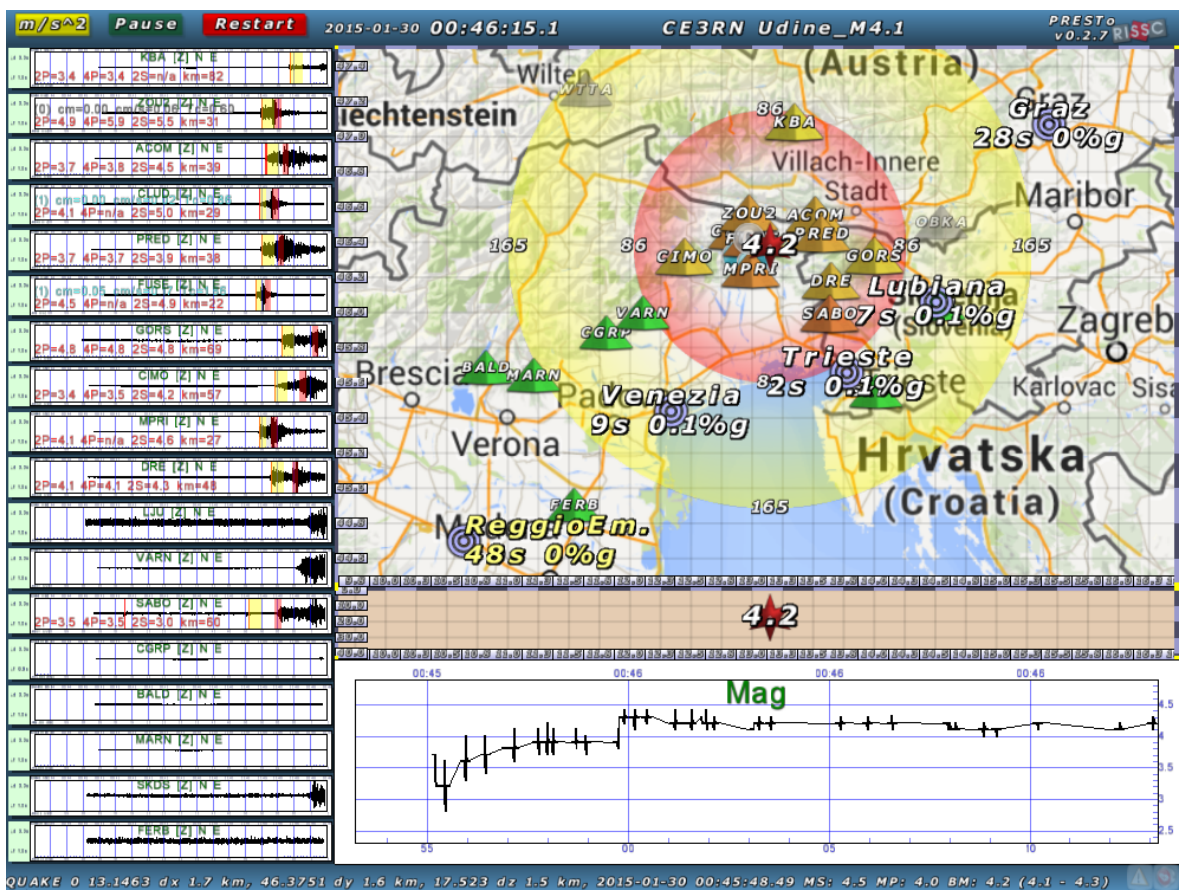

Figure 9. Snapshot of the playback of the PRESTo system during the 30 January $2015 M_{\mathrm{L}}=4.1$ earthquake (event no. 24, Table 1) using new parameters of the $\log (P d)$ vs. $M$ relationship.

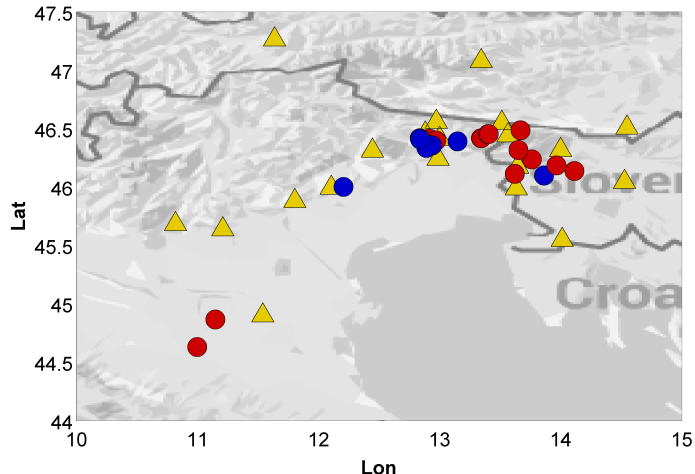

Figure 10. $\mathrm{CE}^{3} \mathrm{RN}$ stations (yellow). Delays less than $15 \mathrm{~s}$ (blue) or larger (red).

the performance of the EEWS would improve, considering the actual $\mathrm{CE}^{3} \mathrm{RN}$ network configuration. In particular, for such a scenario, we found that three major centres in the region (i.e. Pordenone, Trieste, and Ljubljana) could fall within isoseismal level VI (i.e. experiencing a strong ground shaking) but potentially benefit from a lead time longer than $10 \mathrm{~s}$. As discussed by Goltz (2002), when the population is trained to rapidly respond and take protective measures (e.g. duck and cover, turn off gas burners, move away from windows or equipment, etc.), even fewer than $10 \mathrm{~s}$ can help to reduce the risk of injury from an earthquake's secondary effects.
During the period May-December 2014, PRESTo detected in real time 23 earthquakes in the magnitude range 1.7 to 4.1 , of which 14 were correctly detected, while 4 and 3 events resulted in missed and false alerts, respectively. Despite the testing period still being too short to come up with definitive conclusions, it seems that the EEWS given by the integration of PRESTo and $\mathrm{CE}^{3} \mathrm{RN}$ is efficient with respect to earthquakes that occur nearby the area with higher station density. Nevertheless, more testing and an improvement in the system are necessary to cope with events occurring out of the network, and in general where it has a lower station density. With respect to this last issue, we are evaluating to increase the network density, including in the EEWS also stations with velocimetric sensors.

The testing period of the EEW system is carried out primarily with the goal of highlighting the existence of weak points (i.e. in the hardware, network management and analysis software with respect to the seismicity of the area). In fact, besides the specific characteristics of an EEW algorithm, the performance of an EEW system strongly depends also on technological issues, like for example the efficiency of the data telemetry and the seismic noise level at the stations. For this reason, especially these latter two aspects will be studied in the next tests of the EEWS. Of course, the realisation of the EEWS in the area monitored by $\mathrm{CE}^{3} \mathrm{RN}$ will be accompanied by an extensive activity of communication and training, specifically tailored for both the population and the different stakeholders. 
Besides the standard application of EEW, the use of PRESTo in the area surveyed by $\mathrm{CE}^{3} \mathrm{RN}$ will give a potential benefit to local civil protection agencies. In the case of a very strong shock, the standard monitoring network equipped with modern BB sensors has a saturation zone that may hamper immediate response (e.g. see Fig. 2 from Faenza et al., 2011) in a radius of the order of $100 \mathrm{~km}$. This means that the epicentral location is available when the strongest $\mathrm{S}$-wave phase has already affected the area. On the contrary, an EEW system may broadcast the information to civil protection centres before the strong ground motion can cause potential failure or hampering of the communication system. Hence, civil protection would have the information necessary to act immediately, according to the severity of the situation.

Acknowledgements. We would like to thank the Associate Editor J. Clinton, C. Cauzzi and an anonymous reviewer for their comments and suggestions that allowed us to significantly improve the manuscript's content and form.

This work has been partially supported by the REAKT-Strategies and tools for Real Time Earthquake RisK ReducTion FP7 European project funded by the European Community's Seventh Framework Programme (FP7/2007-2013) under grant agreement no. 282862.

Edited by: J. Clinton

Reviewed by: C. Cauzzi and two anonymous referees

\section{References}

Akkar, S. and Bommer, J. J.: Empirical prediction equations for peak ground velocity derived from strong-motions records from Europe and the Middle East, Bull. Seismol. Soc. Am., 97, 511530, 2007.

Alcik, H., Özel, O., Apaydin, N., and Erdik, M.: A study on warning algorithms for Istanbul earthquake early warning system, Geophys. Res. Lett., 36, L00B05, doi:10.1029/2008GL036659, 2009.

Allen, R. M., Gasparini, P., Kamigaichi, O., and Böse, M.: The status of earthquake early warning around the world: an introductory overview, Seismol. Res. Lett., 80, 682-693, 2009.

Böse, M., Ionescu, C., and Wenzel, F.: Earthquake Early Warning for Bucharest, Romania: Novel and revised scaling relations, Geophys. Res. Lett., 34, L07302, doi:10.1029/2007GL029396, 2007.

Böse, M., Hauksson, E., Solanki, K., Kanamori, H., and Heaton, T. H.: Real-time testing of the on-site warning algorithm in Southern California and its performance during the July 29, $2008 M_{\mathrm{W}} 5.4$ Chino Hills earthquake, Geophys. Res. Lett., 36, L00B03, doi:10.1029/2008GL036366, 2009.

Bragato, P. L., Costa, G., Gallo, A., Gosar, A., Horn, N., Lenhardt, W., Mucciarelli, M., Pesaresi, D., Steiner, R., Suhadolc, P., Tiberi, L., Živčić, M., and Zoppé, G.: The Central and Eastern European Earthquake Research Network - CE ${ }^{3}$ RN, EGU General Assembly 2014, 27 April-2 May 2014, Vienna, Austria, 2014.
Carulli, G. B. and Slejko, D.: The 1976 Friuli (NE Italy) earthquake, Giornale di Geologia Applicata, 1, 147-156, 2005.

Colombelli, S., Amoroso, O., Zollo, A., and Kanamori, H.: Test of a Threshold-Based Earthquake Early Warning Using Japanese Data, Bull. Seismol. Soc. Am., 102, 1266-1275, doi:10.1785/0120110149, 2012..

Espinosa-Aranda, J. M., Cuellar, A., Garcia, A., Ibarrola, G., Islas, R., Maldonado, S., and Rodriguez, F. H.: Evolution of the Mexican Seismic Alert System (SASMEX), Seismol. Res. Lett., 80, 694-706, 2009.

Faenza, L., Lauciani, V., and Michelini, A.: Rapid determination of the shakemaps for the L'Aquila main shock: a critical analysis, Bollettino di Geofisica Teorica ed Applicata, 52, 407-425, doi:10.4430/bgta0020, 2011.

Giorgetti, F.: Isoseismal map of the May 6, 1976 Friuli earthquake, Boll. Geofis. Teor. Appl., 19, 707-714, 1976.

Goltz, J. D. L.: Introducing earthquake early warning in California: A summary of social science and public policy issues, technical report, Governor's Off. of Emergency Serv., Pasadena, Calif., 2002.

Gruppo di lavoro MPS: Redazione della mappa di pericolosita ' sismica prevista dall'Ordinanza PCM 3274 del 20 marzo 2003, Rapporto conclusivo per il dipartimento di Protezione Civile, INGV, aprile 2004, Milano, Roma, 65 pp. + 5 appendici, available at: http://zonesismiche.mi.ingv.it/elaborazioni/ (last access: 31 March 2015), 2004.

Heinloo, A.: SeedLink design notes and configuration tips, http:/geofon.gfz-potsdam.de/geofon/seiscomp.de/geofon/ seiscomp/seedlink.html (last access: 31 March 2015), 2000.

Horiuchi, S., Negishi, H., Abe, K., Kamimura, A., and Fujinawa, Y.: An automatic processing system for broadcasting system earthquake alarms, Bull. Seismol. Soc. Am., 95 347-353, 2005.

Hoshiba, M.: Real-time correction of frequency-dependent site amplification factors for application to Earthquake Early Warning, Bull. Seismol. Soc. Am., 103, 3179-3188, doi:10.1785/0120130060, 2013.

Iannaccone, G., Zollo, A., Elia, L., Convertito, V., Satriano, C., Martino, C., Festa, G., Lancieri, M., Bobbio, A., Stabile, T. A., Vassallo, M., and Emolo, A.: A prototype system for earthquake early-warning and alert management in southern Italy, Bull. Earthq. Eng., 8, 1105-1129, doi:10.1007/s10518-009-9131-8, 2010.

Lancieri, M. and Zollo, A.: Bayesian approach to the realtime estimation of magnitude from the early $\mathrm{P}$ and $\mathrm{S}$ wave displacement peaks, J. Geophys. Res., 113, B12302, doi:10.1029/2007JB005386, 2008.

Lomax, A., Satriano, C., and Vassallo, M.: Automatic picker developments and optimization: FilterPicker - a robust, broadband picker for real-time seismic monitoring and earthquake early-warning, Seismol. Res. Lett., 83, 531-540, doi:10.1785/gssrl.83.3.531, 2012.

Luzi, L., Hailemikael, S., Bindi, D., Pacor, F., Mele, F., and Sabetta, F.: ITACA (ITalian ACcelerometric Archive): a web portal for the dissemination of Italian strong-motion data, Seismol. Res. Lett., 79, 716-722, 2008.

OGS: Bollettino della Rete Sismometrica del Friuli-Venezia Giulia e del Veneto, OGS (Istituto Nazionale di Oceanografia e di Geofisica Sperimentale), Centro di Ricerche Sismologiche, Udine, Italy, 1995-2013. 
Pacor, F., Paolucci, R., Ameri, G., Massa, M., and Puglia, R.: Italian strong motion records in ITACA: overview and record processing, Bull. Earthq. Eng., 9, 1723-1739, doi:10.1007/s10518-0119327-6, 2011.

Peng, H. S., Wu, Z. L., Wu, Y. M., Yu, S. M., Zhang, D. N., and Huang, W. H.: Developing a prototype earthquake early warning system in the Beijing Capital Region, Seismol. Res. Lett., 82, 394-403, 2011.

Picozzi, M., Colombelli, S., Zollo, A., Carranza, M., and Buforn, E.: A Threshold-Based Earthquake Early-Warning System for Offshore Events in Southern Iberia, Pure Appl. Geophys., doi:10.1007/s00024-014-1009-2, in press, 2014.

Picozzi, M., Emolo, A., Martino, C., Zollo, A., Miranda, N., Verderame, G., Boxberger, T., and the REAKT Working Group: Earthquake Early Warning System for Schools: A Feasibility Study in Southern Italy, Seismol. Res. Lett., 86, 398-412, doi:10.1785/0220140194, 2015a.

Picozzi, M., Zollo, A., Brondi, P., Colombelli, S., Elia, L., and Martino, C.: Exploring the Feasibility of a Nation-Wide Earthquake Early Warning System in Italy, J. Geophys. Res.-Solid, doi:10.1002/2014JB011669, in press, 2015b.

Satriano, C., Lomax, A., and Zollo, A.: Real-Time Evolutionary Earthquake Location for Seismic Early Warning, Bull. Seismol. Soc. Am., 98, 1482-1494, doi:10.1785/0120060159, 2008.

Satriano, C., Wu, Y.-M., Zollo, A., and Kanamori, H.: Earthquake early warning: Concepts, methods and physical grounds, Soil Dynam. Earthq. Eng., 31, 106-108, doi:10.1016/j.soildyn.2010.07.007, 2010.
Satriano, C., Elia, L., Martino, C., Lancieri, M., Zollo, A., and Iannaccone, G.: PRESTo, the earthquake early warning system for Southern Italy: concepts, capabilities and future perspectives, Soil. Dyn. Earthq. Eng., 31, 137-153, doi:10.1016/j.soildyn.2010.06.008, 2011.

SeisComP: Seismological communication processor, 2009, http: //geofon.gfz-potsdam.de/geofon/seiscompS, last access: January 2010 .

Steim, J. M. and Reimiller, R. D.: Timeliness of Data Delivery from Q330 Systems, Seismol. Res. Lett., 85, 844-851, doi:10.1785/0220120170, 2014.

Wu, Y. M. and Zhao, L.: Magnitude estimation using the first three seconds P-wave amplitude in earthquake early warning, Geophys. Res. Lett., 33, L16312, doi:10.1029/2006GL026871, 2006.

Zollo, A., Amoroso, O., Lancieri, M., Wu, Y. M., and Kanamori, H.: A threshold-based earthquake early warning using dense accelerometer networks, Geophys. J. Int., 183, 963-974, doi:10.1111/j.1365-246X.2010.04765.x, 2010.

Zollo, A., Colombelli, S., Elia, L., Emolo, A., Festa, G., Iannaccone, G., Martino, C., and Gasparini, P.: An Integrated Regional and On-Site Earthquake Early Warning System for Southern Italy: Concepts, Methodologies and Performances, in: Early Warning for Geological Disasters, Advanced Technologies in Earth Sciences, edited by: Wenzel, F. and Zschau, J., Springer, Berlin, Heidelberg, 117 pp., doi:10.1007/978-3-642-12233-0_7, 2014. 